\title{
ELECTROCARDIOGRAPHY AS A MEANS OF PRESAGING CARDIAC PAIN
}

\author{
BY \\ WILLIAM EVANS \\ From the Cardiac Department of the London Hospital
}

Received June 27, 1961

A medical examination that includes the recording of an electrocardiogram has now become a routine procedure, with the object of discovering coronary arterial disease. It is often used in those who hold responsible positions in commerce or industry, in applicants for large insurance policies, and in those entering superannuation schemes.

It is not rare for the electrocardiogram to show small deformities in uncomplaining adults. Such changes when found in patients with chest pain are evidence of cardiac infarction, which at the time is limited to a small area but may ultimately extend to involve a larger portion of heart muscle. The significance of the same lesser cardiographic changes in subjects without pain, has not, however, been determined with certainty, and there is need to learn of the progress of such cases both in regard to the destiny of the cardiographic deformities and their liability to develop cardiac pain in the future. Moreover, in a patient who contracts cardiac pain from cardiac infarction, it would be an advantage to know whether the cardiogram, recorded either purposely or fortuitously during the years preceding the onset of pain, can anticipate the subsequent entry of this symptom. A material gain in our knowledge of the course of this illness will have taken place if such graphomancy, or divination of cardiac pain from the electrocardiogram of coronary arterial disease, were possible. It is with these problems that the present paper is concerned.

The Investigation Described. A record of the symptomatology and the clinical findings in 5000 consecutive subjects of 35 years of age or older was supplemented in each case by an electrocardiographic and cardioscopic examination.

The cardiogram consisted of the four standard limb leads, I, II, III, and IIIR (lead III during deep inspiration), and the bipolar chest leads, CR1, CR4, and CR7. The CR leads were used deliberately in that they portray more clearly the lesser changes associated with small myocardial lesions, than do the so-called unipolar V leads.

The cardiogram was studied specially in relation to the presence or absence of heart disease and particularly of chest pain.

\section{FINDINGS}

For the purpose of classifying the electrocardiographic changes in relation to the clinical findings in this series, the cases were arranged in four main groups. The first group included patients with some form of heart disease. The second included patients with symptoms that suggested heart pain but were proved to be due to other causes after a detailed examination. The third group consisted of subjects who had neither symptoms nor signs of heart disease, while the fourth was made up of symptomless patients whose electrocardiogram was abnormal. The numerical distribution of the patients among the separate groups is shown in Table $I$, and it is the findings in the third and fourth groups that form the basis of this paper. 
TABLE I

Classification of the Electrocardiographic Findings in 5000 Consecutive Cases, Aged 35 Years or older

Group I. Patients with some form of heart disease with its corresponding electrocardiogram (3379)*

Group II. Patients ultimately shown to be healthy, with non-cardiac chest pain and a normal electrocardiogram (963) Group III. Healthy symptomless subjects with a normal electrocardiogram (550)

Group IV. Symptomless and apparently healthy subjects, who had an abnormal electrocardiogram, consistent with a myocardial lesion (108), arranged in three classes as under:

(a) Subsequently developing cardiac pain (27);

(b) Progress known, and remaining symptomless (30); and

(c) Progress not ascertained (51)

* Numerals denote number of cases in each group.

\section{Group I. Patients with Heart Disease and an Electrocardiogram to Correspond}

This group held 3379 patients, and the majority suffered from cardiac pain following cardiac infarction when the cardiogram showed deformities conforming with the situation and extent of the infarct. Among these patients with cardiac infarction no instance was met, where a cardiogram recorded fortuitously before the onset of cardiac pain had been a normal tracing; nor was there an example of recovery of a cardiogram once deformed by infarction.

The remaining patients suffered from valvular, hypertensive, or congenital heart disease, and the electrocardiogram, usually abnormal, was in keeping with the kind and degree of ventricular preponderance that might be present, and with any form of arrhythmia should it be added.

\section{Group II. With Symptoms suggesting Heart Disease but with a Normal Electrocardiogram}

Into this group fell 963 cases. Palpitation was a common symptom, which a subsequent examination explained as functional in kind or arising from extrasystoles or short episodes of atrial tachycardia. Chest pain was a commoner symptom and this not infrequently simulated cardiac pain in respect of its character, situation, and spread, and of its reaction to exercise and to rest. A cardiogram in these cases, however, proved to be a normal tracing, and for this reason, coronary arterial disease as the source of the pain was excluded. A pre-requisite to a confident assumption that a strictly normal cardiogram excluded pain in these cases meant a close acquaintanceship with the lesser cardiographic deformities that tell of a small myocardial injury at the time. Whenever an exercise cardiogram was recorded in cases in this group, it too proved to be a normal test. Moreover, when the subsequent progress of these patients was overseered through two to ten years, no instance was found where the cardiogram, or the clinical history, told of the development of true cardiac pain from cardiac infarction.

\section{Group III. Symptomless Subjects with Normal Electrocardiogram}

There were 550 cases in this group. Their ages were 35 years or over, and were comparable with those of the other groups; they were evenly distributed in the fifth to the seventh decades, and a few were over 77 years of age. Absence of symptoms and of physical and radiological signs in all of them, as well as a normal cardiogram, ensured the absence of heart disease. The first examination took place ten years before in one-third, and more than five years before in almost two-thirds of them. None was recalled for subsequent examination following the reassurance imparted to them at the first, but many returned on their own accord because some symptoms had set in; this often took the form of chest pain, but once more in none of these was the electrocardiogram abnormal as evidence of cardiac pain from the entry of cardiac infarction.

\section{Group IV. Symptomless Patients with Abnormal Electrocardiogram}

There were 108 cases in this group, 74 men and 34 women. The ages varied from 35 to 80, and the average age for the group was 57 years. 


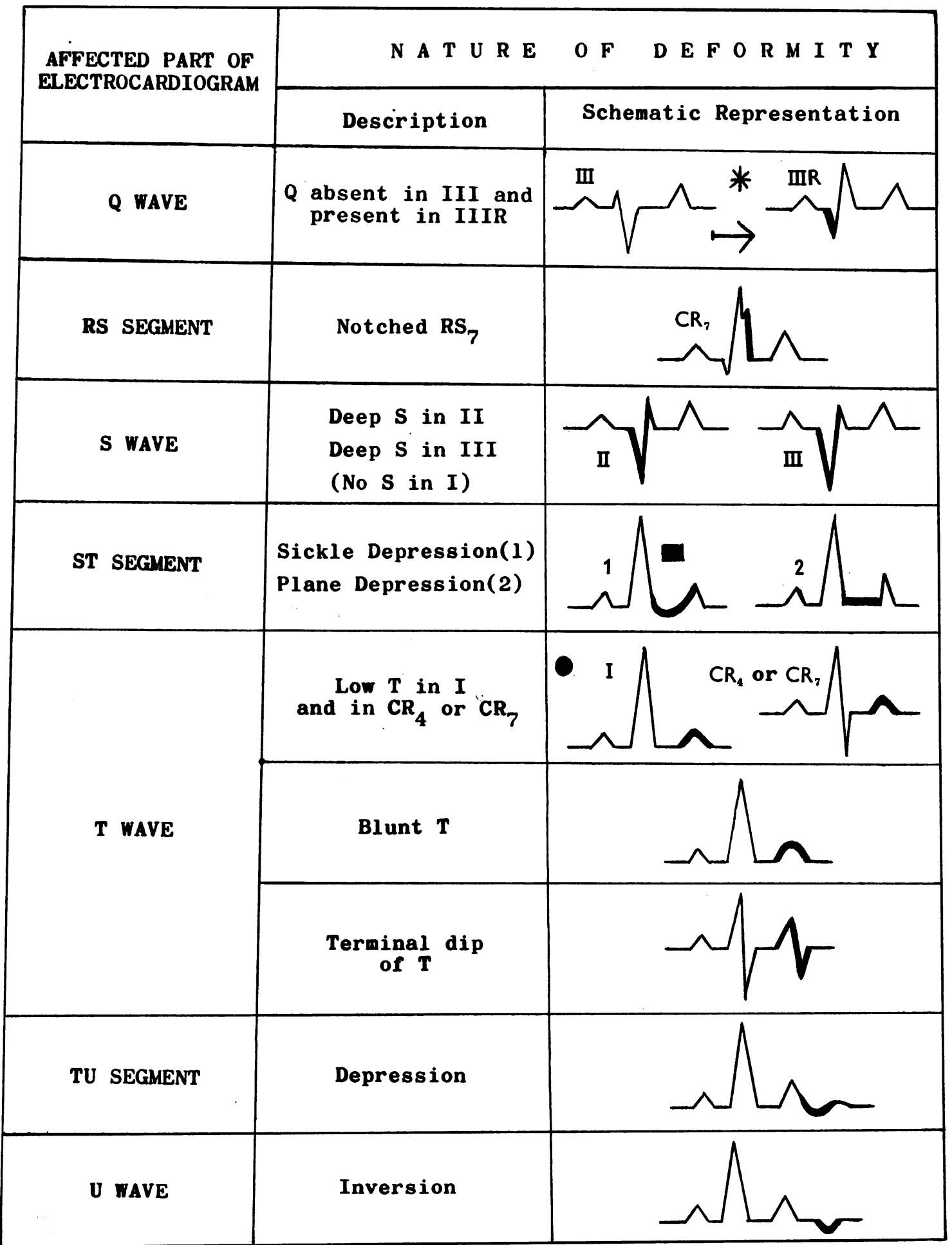

FIG. 1.-Diagrammatic representation of the lesser electrocardiographic changes arising from cardiac infarction of limited distribution.

* provided diaphragm is depressed during deep inspiration.

provided digitalization is absent.

provided exercise electrocardiogram gives a positive reaction. 
A clinical history and physical examination had failed to find any blemish, but the cardiogram in each showed the lesser deformities so commonly found in patients with cardiac pain from coronary arterial disease. That such changes were found in uncomplaining subjects caused no surprise because we had previously met with 26 instances when we assembled 70 examples of painless cardiac infarction (Evans and Sutton, 1956).

In the interrogation of these patients, an inquiry to confirm the absence of pain or a like symptom affecting either chest, arms, shoulders, back or abdomen, was a special care. Similarly, palpitation from atrial tachycardia or fibrillation, which might have heralded painless cardiac infarction, was excluded. The blood pressure was never raised at the time and subsequent cardioscopy showed no enlargement of the heart, while digitalis medication was never the cause of the cardiographic deformities exhibited by patients in this group. Instances of right bundle-branch block only were omitted as a rule from this class because it could sometimes be an innocent and fortuitous finding.

The initial electrocardiogram, recorded at a time when pain was not a symptom, showed either one or more of the changes accepted as being due to cardiac infarction that at the time was limited to a small portion of the myocardium. These changes are illustrated diagrammatically in Fig. 1. The most common deformity was a depression of the S-T segment, and this was usually present in leads that located the injury in the postero-lateral aspect of the left ventricle, namely in leads I, III, IIIR, and CR7.

In that the 108 patients with this abnormal cardiogram denied the presence of chest pain, they were given reassurance, and they were not invited to attend for further examination. The subsequent progress in 57 of them has, however, become known, and 11 of them attended for reexamination. Emphasis is again given to the fact that no effort was made to bring the remaining 51 for re-examination, since it was considered wrong to risk a recrudescence of the suspicion that anything ailed the heart, after the encouragement given to them at their first attendance when they were symptom-free in spite of small changes in the cardiogram. Of the 57 patients whose progress is now known, 30 remain free from symptoms, while cardiac pain has appeared in the remaining 27 , and it is to this group that special attention is now directed.

\section{Graphomancy of Cardiac Pain}

Among the 27 patients there were 23 men and 4 women. Their ages varied from 40 to 78 , and the average was 55 years: 9 of them were 55 or younger. The interval that had elapsed between finding an abnormal electrocardiogram and the onset of cardiac pain varied from 5 months to 13 years, and the average for the group was 4 years: the period was 3 years or less in 13 and longer than 3 years in 14 patients. Of course these findings do not reflect accurately the time that elapsed between the appearance of the early cardiographic signs and the onset of pain, because it was not possible to discover how long these deformities, found at the first examination, had existed. Twelve of the 27 patients have died after surviving for an average period of five years following the discovery of the abnormal cardiogram. It is not possible to give the incidence with which cardiac pain sets in among uncomplaining subjects who show these early cardiographic signs because the fate of the 51 cases undergoing a single examination is not known and a request that they should attend for further examination is still considered unjustified.

With the onset of cardiac pain, the deformity in the cardiogram had become exaggerated in all save one, but in six it could still be classed as belonging to those styled as lesser signs. In the remaining patients the deformity was greatly accentuated, showing frank inversion of the $T$ wave (Fig. 2 to 6).

Alongside the present series of 108 patients with limited cardiac infarction, initially free from cardiac pain, there were assembled 1250 patients who showed the same lesser cardiographic signs in the presence of cardiac pain at the first examination. It was not known whether the cardiographic changes in these patients had antedated the onset of pain, but such examples appear to confirm that the size of the infarct and the extent of the cardiographic signs do not determine the presence 


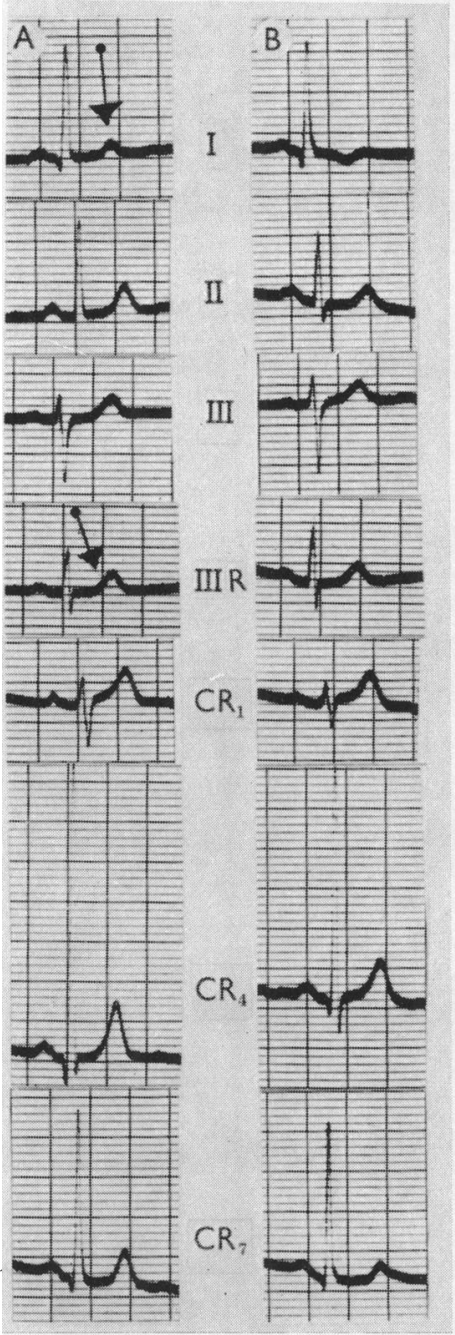

FIG. 2.

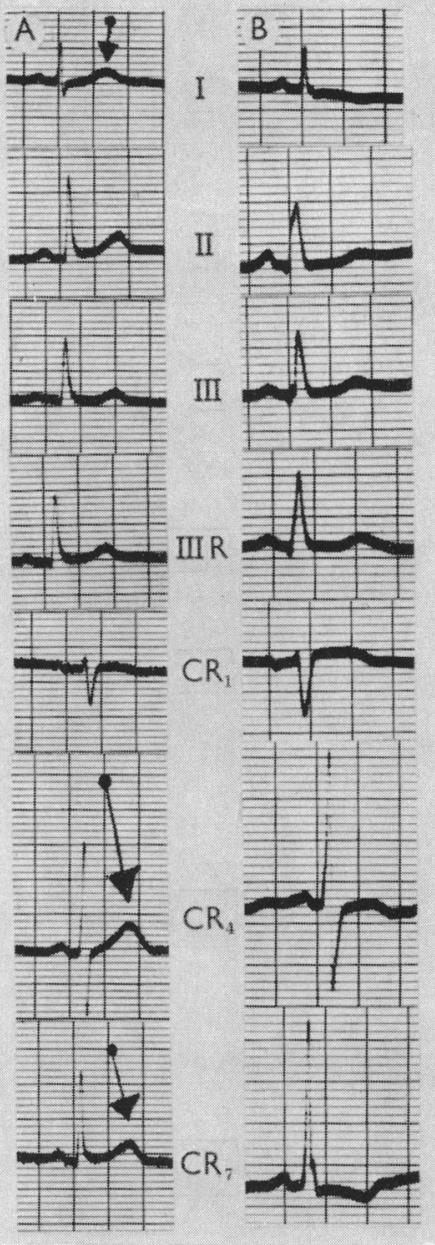

FIG. 3.

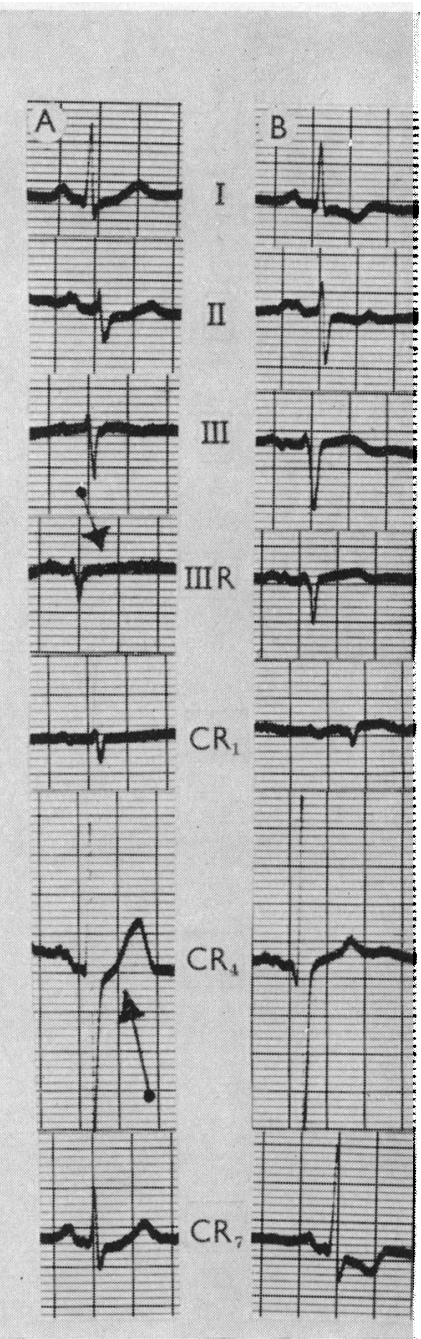

FIG. 4.

FIG. 2.-Cardiac pain was absent when (A) was recorded: it shows S-T depression in leads I and IIIR. More obvious changes in (B) recorded two years later when cardiac pain had set in.

FIG. 3.-Cardiac pain was absent when (A) was recorded: it shows a blunt $\mathrm{T}$ wave in leads I, CR4, and CR7. More obvious changes in (B) recorded two years later when cardiac pain had set in.

FIG. 4.-Cardiac pain was absent when (A) was recorded: it shows S-T depression in leads IIIR and CR4. More obvious changes in (B) recorded two years later when cardiac pain had set in.

or absence of pain: thus, it is unusual to find a patient who exhibits frank inversion of $T$ waves from cardiac infarction in the absence of a past history of cardiac pain, unless a bout of arrhythmia has accompanied the infarction. It is known that when such arrhythmia in the form of atrial tachycardia or fibrillation coincides with the onset of cardiac infarction, pain is frequently absent (Evans and Sutton, 1956). Such instances, therefore, can simulate the group now under discussion, when the associated palpitation has subsided and is not mentioned in the history. Their 

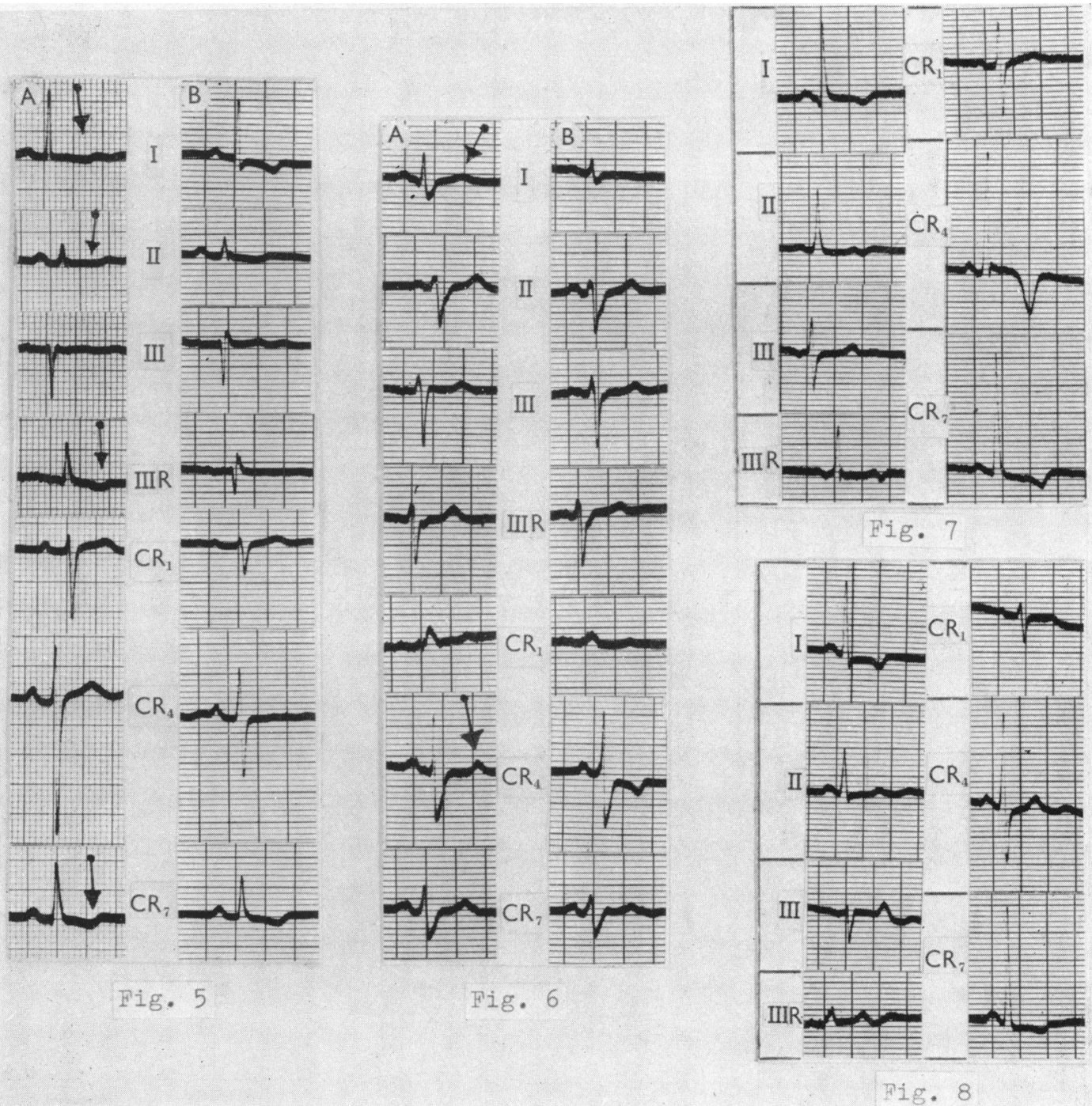

Fig. 5.-Cardiac pain was absent when (A) was recorded: it shows S-T depression in leads I, II, IIIR, and CR7. More obvious changes in (B) recorded four years later when cardiac pain had set in.

Fig. 6.-Cardiac pain was absent when (A) was recorded: it shows significant S-T depression in CR4 in addition to a right bundle-branch block. More obvious changes in (B) recorded a year later when cardiac pain had set in.

Fig. 7.-Changes of cardiac infarction in a patient without chest pain, whose illness commenced with a paroxysm of tachycardia.

FIG. 8.-Changes of cardiac infarction in a patient without chest pain, whose illness commenced with a paroxysm of tachycardia.

recognition comes, however, from finding a cardiogram that shows frank and lasting inversion of the $T$ wave (Fig. 7 and 8 ) in the absence of cardiac pain.

In the 11 patients in whom a second cardiogram was recorded after an interval of more than two years and cardiac pain continued to be absent, the second tracing showed exaggeration of the deformities appearing in the first tracing in only two instances, and in one of these the $T$ wave was actually 
inverted. The deformities were less conspicuous in another two and in the remaining seven they were unchanged.

The age factor did not appear to influence the incidence of the pain. Although the preponderance of men over women is a notable feature in the 27 patients who developed cardiac pain, compared with the sex distribution in the whole series, namely 6 to 1 compared with 2 to 1 , yet this male preponderance is a feature of the group of 30 patients in whom it is known that cardiac pain has not yet set in after an average interval of 6 years (Table II).

TABLE II

The Known Progress of 57 Uncomplaining Adults whose Electrocardiogram Showed Evidence of a Limited CARDIAC INFACTION

\begin{tabular}{|c|c|c|c|c|c|}
\hline \multirow[b]{2}{*}{ Description of cases } & \multirow[b]{2}{*}{ Number } & \multicolumn{2}{|c|}{ Sex } & \multirow[b]{2}{*}{$\begin{array}{l}\text { Average } \\
\text { age }\end{array}$} & \multirow{2}{*}{$\begin{array}{l}\text { Average interval (in } \\
\text { years) between first } \\
\text { examination and } \\
\text { either onset of pain } \\
\text { or progress report }\end{array}$} \\
\hline & & Male & Female & & \\
\hline Patients who later developed cardiac pain .. & 27 & 23 & 4 & 55 & 4 \\
\hline $\begin{array}{l}\text { Patients known to be remaining free from } \\
\text { cardiac pain }\end{array}$ & 30 & 23 & 7 & 59 & 6 \\
\hline $\begin{array}{cccccc}\text { Patients who have not yet sought re-exami- } \\
\text { nation } & . & \ldots & \ldots & \ldots & \ldots\end{array}$ & 51 & 28 & 23 & 56 & $7^{*}$ \\
\hline $\begin{array}{l}\text { Entire group of uncomplaining subjects with } \\
\text { an abnormal cardiogram }\end{array}$ & 108 & 74 & 34 & 57 & - \\
\hline
\end{tabular}

* Interval between first examination and present time.

It is likely that the state of the collateral circulation, above all else, decides the presence or absence of pain in patients whose cardiograms give proof that the infarct at the time is limited to a small area. Experience with the exercise electrocardiogram led us (Evans and Lloyd-Thomas, 1961) to suggest that the incidence of pain had a definite meaning in patients in whom the cardiogram showed these lesser deformities, inasmuch as the exercise tracing in those with pain showed far greater exaggeration of the deformity of the resting cardiogram than in those without pain. We concurred with the opinion expressed by Biörck (1946) and Master (1950) that the exercise test in those instances reflected the efficiency of the alternate blood supply provided by the collateral circulation.

Moreover, in a patient in whom cardiac pain is absent at the time though a resting electrocardiogram, fortuitously recorded, shows the lesser changes associated with a limited cardiac infarction, should the tracing following exercise show major changes, it predicts the future onset of cardiac pain with greater certainty than if the changes after exercise were hardly exaggerated.

In the 27 patients in whom cardiac pain developed subsequent to the first examination at which the lesser cardiographic deformities were present, the more gross signs that had appeared in the tracing at the second examination when pain had set in were an exaggeration of the previous changes and indicated a spread of the initial area of cardiac injury and not an involvement of the collateral coronary blood supply on the opposite side.

\section{SummaRY AND CONCLUSIONS}

The electrocardiogram recorded in 658 consecutive symptom-free adults of 35 years of age or older, was normal in 550.

In the remaining 108 patients the cardiogram was abnormal, exhibiting the lesser changes that in the past have been identified in patients with cardiac pain as indicating cardiac infarction, limited 
at the time to a small area of the myocardium. In these patients special care was taken to inquire about symptoms, and particularly about pain or a like complaint, which might indicate the presence of coronary arterial disease. Moreover, when the abnormal cardiogram came to light, a more direct inquiry about the presence of pain was made, but never in a way to suggest to these uncomplaining subjects that anything abnormal had been discovered during a routine examination. For the same reason, namely to avoid introducing unwarranted invalidism, none of the patients has been recalled for further examination.

The average age of this group, made up of 74 men and 34 women, was 57 years.

Each of the 108 patients were given reassurance following the first examination and they were not invited to re-attend, but as time passed the subsequent progress became known in 57 of them. In as many as 27 of these, cardiac pain had set in, but in the remaining 30 pain continued to be absent.

The interval that had elapsed between the first visit and the onset of cardiac pain was three years or less in 13, and longer than three years in 14: the average interval for the group was four years. Of these 27 patients, 12 died within an average period of three years after the first examination.

The deformity in the electrocardiogram had become obviously exaggerated following the appearance of cardiac pain in every patient save one, although in six the tracing could still be regarded as showing only lesser signs.

An efficient collateral coronary circulation decides the delayed onset of pain in these patients, and such cardiac pain sets in when this deteriorates. Thus, in a patient showing the lesser cardiographic changes in the absence of pain, a tracing recorded after exercise will decide the imminence of the symptom, for a strongly positive test indicates its early appearance, while in one where exercise only accentuates the deformity slightly or not at all, pain may not trouble the patient for some time, even several years.

No patient the subject of cardiac pain from cardiac infarction has yet attended, in whom a cardiogram recorded fortuitously within three years of the onset of pain proved to be a strictly normal tracing. Graphomancy, or divination of cardiac pain through the agency of the electrocardiogram, therefore, is a reality.

In that no means is yet within our reach to prevent the progress of coronary arterial atherosclerosis, when the lesser cardiographic signs of a limited cardiac infarction are discovered in a symptomless patient, reassurance should not be withheld, in order to avoid premature invalidism.

Biörck, G. (1946). Brit. Heart J., 8, 17.

\section{REFERENCES}

Evans, W., and Lloyd-Thomas, H. G. (1961). Amer, Heart J., 62, 51.

-, and Sutton, G. C. (1956). Brit. Heart J., 18, 259.

Master, A. M. (1950). Ann. intern. Med., 32, 842. 